\title{
ANALISIS KETERGANTUNGAN MASYARAKAT TERHADAP HASIL HUTAN DI DALAM KAWASAN HUTAN LINDUNG DI DESA DAHA KECEMATAN HU'U KABUPATEN DOMPU PROPINSI NUSA TENGGARA BARAT
}

\author{
Oleh: \\ Fahrirurrahman, Yulia Ratnaningsih \\ Program studi Kehutanan Universitas Pendidikan mandalika \\ Email : Fachryg42@gmail.com
}

\begin{abstract}
Abstrak
Abstrak: Penelitian ini di laksanakan di Kawasan Hutan lindung Yang berlokasi di Desa Daha dengan tujuan : menganalisa tingkat ketergantungan masyarakat terhadap sumber daya hutan, mengetahui faktorfaktor penyebab ketergnatungan masyarakat terhadap sumber daya hutan. Metode yang di gunakan dalam penelitian ini adalah metode deskritif. Berdasarkan hasil penelitian tingkat ketergantungan masyarakat terhadap sumber daya hutan di lihat dari rata-rata adalah tergolong tinggi pada komponen pendapatan,tergolong sangat tinggi pada komponen curahan waktu kerja, tergolong rendah pada komponen sumber konsumsi. Sedangkan untuk tingkat ketergantungan kumulatif masyarakat terhadap Kawasan hutan tergolong tinggi. Di desa Daha terdapat enam faktor penyebab ketergantungan masyarakat terhadap hutan yaitu: penambahan pemasukan secara ekonomi, tingkat Pendidikan rendah, kurangnya lapangan pekerjaan, mengikuti teman, terbiasa dilakukan sejak kecil, dan tidak ada penghasilan tetap
\end{abstract}

Kata Kunci: Tingkat ketergantungan, penyebab ketergantungan, hutan lindung,

\section{PENDAHULUAN}

Di kawasan hutan lindung didesa daha dapat di lihat aktivitas interaksi masyarakat yang begitu aktif keluar masuk kawasan hutan. Aktivitas tersebut tersebut dapat menjadi perhatian yang begitu besar untuk di lakukan penelitian. Hal ini sejalan dengan apa yang di sampaikan oleh Birgantoro dan Nurrochmat (2007), bahwa interaksi sosial masayarakat desa dengan hutan dapat dilihat dari ketergantungan masyarakat sekitar hutan akan sumber-sumber kehidupan dasar seperti air,sumber energi kayu bakar dan bahan makanan yang di hasilkan dari hutan, bahan bangunan dan sumber daya lainny.

Tujuan yang ingin di capai dalam penelitia ini yaitu untuk: Untuk mengetahui tingkat ketergantungan masyarakat terhadap sumber daya hutan serta faktor-faktor penyebab ketergantungan masyarakat terhadap sumber daya hutan.

\section{METODOLOGI PENELITIAN}

Metode penelitian ini yang di gunakan dalam penelitian ini adalah metode deskriptif. Metode deskritif adalah suatu metode dalam meneliti status kelompok manusia, suatu objek, suatu set kondisi, suatu sistem, pemikiran, ataupun suatu kelas peristiwa sekarang. Tujuan dari penelitian deskritif ini adalah untuk membuat deskritif, gambaran atau lukisan secara sistematik, faktual dan akurat mengenai fakta-fakta, sifat-sifat serta hubungan antarafenomena yang di selidiki (Nazir, 2011).

\section{a. Penentuan Sampel}

Peneltian ini menggunakan instrumen utama berupa kuisioner untuk memperoleh informasi. Selain itu digunakan pula beberapa peralatan dokumentasi diantaranya: kamera dan alat hitung. Peralatan tersebut selain sebagai instrumen untuk observasi juga digunakan dalam menganalisis data.

Jumlah Responden pada penelitian ini ditentukan secara kuota sebanyak $10 \%$ yaitu 17 kk responden dari jumlah masyarakat yang ada di dusun Fo'o Kompo Desa Daha sebanyak 173 kepala keluarga (KK). 10\% ini di dasarkan pada pendapat Arikunto (2006) yang menyatakan 
bahwa apabila subyeknya $\leq 100$, lebih baik ambil semuanya hingga penelitiannya merupakan penelitian populasi.

\section{c. Jenis Data}

Jenis data yang digunakan dalam penelitian ini adalah data primer dan data sekunder. Data primer adalah data yang di peroleh peneliti secara langsung (dari tangan pertama). Data sekunder adalah data yang di peroleh dari sumber yang ada.

\section{d. Analsis Data}

Dalam menganalisa data yang di kumpulkan peneliti mengunakan Cara sebagai berikut yaitu:

1. Data yang di kumpulkan berupa data hasil wawancara dengan responden yaitu data dalam potensi sumber daya hasil hutan bukan kayu dan kayu dalam Kawasan hutan desa Daha, selanjutnya di tabulasi dan di olah selanjutnya di analisis secara deskritif.

2. Untuk mengetahui kontribusi hasil hutan bukan kayu dan kayu terhadap pendapatan rumah tangga dalam Kawasan hutan di desa daha adalah aktifitas pemanfaatan hasil hutan bukan kayu dan kayu oleh masyarakat.

3. Kontribusi sumber daya hasil hutan bukan kayu dan kayu terhadap pendapatan rumah tangga, pendapatan rumah tangga berasal dari pendapatan responden dari pemanfaatan hasil hutan bukan kayu dan kayu.

4. Untuk mengetahui presentase pendapatan masyarakat dari kegiatan pemanfaatan hasil hutan bukan kayu dan kayu terhadap total pendapatan masyarakat di hitung dengan menggunakan rumus sebagai berikut:

$$
\mathrm{K}^{\frac{d h}{d h+d l}} \times 100 \%
$$

Keterangan:

$$
\begin{array}{ll}
\text { K } \quad: \text { presentase pendapatan dari manfaat } \\
\\
\text { dh } \quad \text { hasil hutan } \\
\text { dl } \quad: \text { pendapatan dari manfaat hasil hutan } \\
\end{array}
$$

\section{HASIL dan PEMBAHASAN}

Tabel 1. Menunjukan pendapatan rata-rata responden di luar kawasan hutan seperti petani jagung dan peternak sapi. Berdasarkan hasil penelitian tersebut jumlah pendapatan responden di luar kawasan hutan yaitu: petani jagung $\mathrm{Rp}$ 471.000.000/Tahun, peternak sapi Rp 150.000.000/Tahun dan jumlah pendapatan

\begin{tabular}{|c|c|c|c|c|}
\hline \multirow[t]{2}{*}{ No } & \multirow[t]{2}{*}{ Nama Responden } & \multicolumn{3}{|c|}{ Nilai Rata-Rata pendapatan di luar kawasan Hutan } \\
\hline & & petani jagung & peternak sapi & Hasil/Tahun (Rp) \\
\hline 1 & YASIN & 30.000 .000 & & 30.000 .000 \\
\hline 2 & MANSHUR & 24.000 .000 & & 24.000 .000 \\
\hline 3 & SAMSUDIN & 39.000 .000 & 20.000 .000 & 59.000 .000 \\
\hline 4 & A.LANDA & 66.000 .000 & 10.000 .000 & 76.000 .000 \\
\hline 5 & RAMANSYAH & 18.000 .000 & & 18.000 .000 \\
\hline 6 & MUHDAR & 27.000 .000 & 20.000 .000 & 47.000 .000 \\
\hline 7 & MUHLIS & 33.000 .000 & 10.000 .000 & 43.000 .000 \\
\hline 8 & JAENAL AL.HAKIM & 21.000 .000 & & 21.000 .000 \\
\hline 9 & SAMLAH & 15.000 .000 & 30.000 .000 & 45.000 .000 \\
\hline 10 & M.TAHIR & 21.000 .000 & 10.000 .000 & 31.000 .000 \\
\hline 11 & SUDARNO & 15.000 .000 & & 15.000 .000 \\
\hline 12 & AMRIN & 15.000 .000 & & 15.000 .000 \\
\hline 13 & FATU RAHMAN & 36.000 .000 & 20.000 .000 & 56.000 .000 \\
\hline 14 & KADASU AMEN & 24.000 .000 & 20.000 .000 & 44.000 .000 \\
\hline 15 & SARIF HIDAYAT & 21.000 .000 & & 21.000 .000 \\
\hline 16 & AHMAD & 36.000 .000 & & 36.000 .000 \\
\hline \multirow[t]{3}{*}{17} & JAMALUDIN & 30.000 .000 & 10.000 .000 & 40.000 .000 \\
\hline & Jumlah & 471.000 .000 & 150.000 .000 & 621.000 .000 \\
\hline & Rata-Rata (Rp) & 27.705 .882 & 8.823 .529 & 36.529 .411 \\
\hline
\end{tabular}
rata-rata yaitu petani jagungRp 27.705.882 dan peternak sapi $\mathrm{Rp}$ 8.823.529.

Tabel 1. tingkat pendapatan di luar kawasan hutan.

Sumber: Data primer Diolah Tahun 2020

Berdasarkan tabel 1. Menunjukan hasil pendapatan rata-rata responden adalah $\mathrm{Rp}$ 26.647058 dari 17 responden dan jumlah pendapatan seluruh responden adalah $\mathrm{Rp}$ 453.000.000. dari 17 responden yang memiliki pendapatan tertinggi yaitu A.landa sebesar Rp 76.000.000/Tahun dan pendapatan rata-rata nya sebesar Rp 50.666.667 dan pendapatan terendah yaitu Sudarno dan Amrin sebesar Rp 15.000.000 dan pendapatan rata-rata sebesar Rp 15.000.000.

Tabel 2. Menunjukan hasil pendapatan ratarata responden adalah $\mathrm{Rp} 4.607 .000$ dari 17 responden dan jumlah pendapatan seluruh responden adalah $\mathrm{Rp}$ 78.333.333. dari 17 responden yang memiliki pendapatan tertinggi yaitu Kadasu amen sebesar Rp 18.400.000/Tahun dan pendapatan rata-rata nya sebesar Rp 12.266.667 dan pendapatan terendah yaitu Jaenal al.hakim sebesar Rp 200.000 dan pendapatan rata-rata sebesar Rp 200.000. 
Tabel 2. Tingkat pendapatan Hasil Hutan Bukan Kayu (HHBK)

\begin{tabular}{|c|c|c|c|c|r|}
\hline \multirow{2}{*}{ No } & Nama Responden & \multicolumn{4}{|c|}{ Nilai Rata-Rata Hasil Hutan Bukan Kayu (HHBK) } \\
\cline { 3 - 6 } & Madu (Rp) & $\begin{array}{c}\text { Asam } \\
(\mathbf{R p})\end{array}$ & kemiri (Rp) & $\begin{array}{c}\text { Hasil/Tahun } \\
\text { (Rp) }\end{array}$ \\
\hline 1 & YASIN & $10,000,000$ & 250,000 & 200,000 & $10,450,000$ \\
\hline 2 & MANSHUR & $7,500,000$ & 750,000 & 600,000 & $8,850,000$ \\
\hline 3 & SAMSUDIN & $2,000,000$ & 300,000 & 800,000 & $3,100,000$ \\
\hline 4 & A.LANDA & $3,500,000$ & 500,000 & 800,000 & $4,800,000$ \\
\hline 5 & RAMANSYAH & $3,000,000$ & 800,000 & & $3,800,000$ \\
\hline 6 & MUHDAR & $1,000,000$ & 800,000 & $1,200,000$ & $3,000,000$ \\
\hline 7 & MUHLIS & $2,500,000$ & & & $2,500,000$ \\
\hline 8 & JAENAL AL.HAKIM & & 200,000 & & 200,000 \\
\hline 9 & SAMLAH & $17,000,000$ & $1,000,000$ & $1,200,000$ & $19,200,000$ \\
\hline 10 & M.TAHIR & $13,000,000$ & 600,000 & $1,400,000$ & $15,000,000$ \\
\hline 11 & SUDARNO & $8,000,000$ & & & $8,000,000$ \\
\hline 12 & AMRIN & & 250,000 & 400,000 & 650,000 \\
\hline 13 & FATU RAHMAN & & 600,000 & 800,000 & $1,400,000$ \\
\hline 14 & KADASU AMEN & $17,000,000$ & & $1,400,000$ & $18,400,000$ \\
\hline 15 & SARIF HIDAYAT & $15,000,000$ & & 800,000 & $15,800,000$ \\
\hline
\end{tabular}

sumber: Data primer Diolah Tahun 2020

Tabel 3. Menunjukan hasil pendapatan ratarata responden adalah $\mathrm{Rp} 7.676 .470$ dari 17 responden dan jumlah pendapatan seluruh responden adalah $\mathrm{Rp}$ 130.000.000. dari 17 responden yang memiliki pendapatan tertinggi yaitu M.tahir sebesar Rp 62.000.000/Tahun dan pendapatan rata-rata nya sebesar $\mathrm{Rp} 62.000 .000$ dan pendapatan terendah yaitu Yasin dan Sudarno sebesar $\mathrm{Rp} 250.000$ dan pendapatan rata-rata sebesar $\mathrm{Rp} 250.000$.

Tabel 3. Tingkat pendapatan Hasil Hutan Kayu (HHK)

\begin{tabular}{|c|c|c|c|c|r|}
\hline \multirow{2}{*}{ No } & \multirow{2}{*}{ Nama Responden } & \multicolumn{3}{|c|}{ Nilai Rata-Rata Hasil Hutan Kayu (HHK) } \\
\cline { 3 - 6 } & & Kayu Ular & Kayu Bangunan & Hasil/Tahun (Rp) & Rata-Rata (Rp) \\
\hline 1 & YASIN & 250.000 & & 250.000 & 250.000 \\
\hline 2 & MANSHUR & & 17.500 .000 & 17.500 .000 & 17.500 .000 \\
\hline 3 & SAMSUDIN & 2.500 .000 & & 2.500 .000 & 2.500 .000 \\
\hline 4 & A.LANDA & 2.000 .000 & & 2.000 .000 & 2.000 .000 \\
\hline 5 & RAMANSYAH & 3.750 .000 & & 3.750 .000 & 3.750 .000 \\
\hline 6 & MUHDAR & 1.250 .000 & & 1.250 .000 & 1.250 .000 \\
\hline 7 & MUHLIS & 1.250 .000 & & 1.250 .000 & 1.250 .000 \\
\hline 8 & JAENAL AL.HAKIM & 1.875 .000 & & 1.875 .000 & 1.875 .000 \\
\hline 9 & SAMLAH & & 25.000 .000 & 25.000 .000 & 25.000 .000 \\
\hline 10 & M.TAHIR & & 62.000 .000 & 62.000 .000 & 62.000 .000 \\
\hline 11 & SUDARNO & 250.000 & & 250.000 & 250.000 \\
\hline 12 & AMRIN & 1.250 .000 & & 1.250 .000 & 1.250 .000 \\
\hline 13 & FATU RAHMAN & 1.250 .000 & & 1.250 .000 & 1.250 .000 \\
\hline 14 & KADASU AMEN & 3.750 .000 & & 3.750 .000 & 3.750 .000 \\
\hline 15 & SARIF HIDAYAT & 2.250 .000 & & 2.250 .000 & 2.250 .000 \\
\hline 16 & AHMAD & 2.500 .000 & & 2.500 .000 & 2.500 .000 \\
\hline 17 & JAMALUDIN & 1.875 .000 & & 1.875 .000 & 1.875 .000 \\
\hline & Jumlah & 26.000 .000 & 104.500 .000 & 130.500 .000 & 130.500 .000 \\
\hline & Rata-Rata (Rp) & 1.529 .411 & 6.147 .058 & 7.676 .470 & 7.676 .470 \\
\hline
\end{tabular}

Sumber: Data primer Diolah Tahun 2020

Tabel 4 menunjukan kriteria pendapatan masyarakat di dalam kawasan hutan lindung di Desa Daha.Kriteria ini di tetapkan dari hasil pendapatan.Responden yang memanfaatkan hutan sebagai sumber penghasilan. Pemilihan kriteria di dapat dari hasil hutan yang produktif untuk di jual oleh responden pada kawasan hutan.dari kriteria di dapatkan bahwa pendapatan responden berada pada kriteria sangat tinggi 0 orang $(0 \%)$,tinggi 1 orang $(12,57 \%)$, sedang 3 orang $(14,25 \%)$, rendah 5 orang $(20,45 \%)$, dan sangat rendah 9 orang $(52,73 \%)$. Dari kompenen pendapatan ,responden di kawasan hutan lindung di Desa Daha sangat rendah tergolong pada kriteria dengan kontribusi pendapatan sangat rendah 9 orang $(52,73 \%)$ dari 17 orang responden.

Tabel 4. Tingkat keterngatungan dari komponen pendapatan

\begin{tabular}{|l|l|c|l|}
\hline $\begin{array}{l}\text { Interval } \\
(\%)\end{array}$ & Kriteria & $\begin{array}{l}\text { Jumlah } \\
\text { Responden }\end{array}$ & $\mathbf{\%}$ \\
\hline $81-100$ & $\begin{array}{l}\text { Sangat } \\
\text { tinggi }\end{array}$ & 0 & 0 \\
\hline $61-80$ & Tinggi & 1 & 12,2 \\
\hline $41-60$ & Sedang & 3 & 14,25 \\
\hline $21-40$ & Rendah & 5 & 20,45 \\
\hline $0-20$ & $\begin{array}{l}\text { Sangat } \\
\text { rendah }\end{array}$ & 9 & 52,73 \\
\hline Jumlah & & $\mathbf{1 7}$ & $\mathbf{1 0 0}$ \\
\hline
\end{tabular}

Sumber : Data primer Diolah Tahun 2020

\section{KESIMPULAN}

Berdasarankan dari hasil penelitian dan pembahasan maka dapat di tarik kesimpulan yang pertama adalah tingkat ketergantungan masyarakat Desa Daha terhadap sumber daya hutan di kawasan hutan lindung, tergolong sangat rendah terlihat segi pendapatan masyarakat itu sendiri.. Yang kedua, terdapat enam faktor penyebab ketergantungan masyarakat terhadap kawasan hutan yaitu penambahan ekonomi, tingkat pendidikan, kurang lapangan pekerjaan, di ajak, sudah sejak kecil dan tidak ada penghasilan tetap dengan presentase tertinggi yang menyebab responden terngatung pada penambahan ekonomi.

\section{SARAN}

Perlu di lakukan pelatihan-pelatihan bagi masyarakat di dalam pengelolaan dan memanfaatkan sumber daya sumber daya yang ada guna untuk mengurangi dampak negatif dari keterngatungan responden terhadap sumber daya hutan. Perlu ada bibingan dan penyuluhan bagi masyarakat terhadap bahaya nya pemanfaatan hasi hutan kayu yang berlebihan yang akan merusak alam dan lingkungan sekitar. 


\section{DAFTAR PUSTAKA}

Ardiansyah,2012 Potensi Kontribusi Hutan Tanaman Rakyat Terhadap Total Pendapatan Rumah Tangga Petani (stdudi kasus : HTR di Desa Cempi Jaya, Kecematan Hu'u Kabupaten Dompu) Skripsi Fakultas Pertanian Universitas Mataram.

Arlene, A., Ekstraksi Minyak Kemiri dengan Metode Soxhlet dan Karakterisasi Minyak Kemiri, 2013, Jurnal Teknik Kimia USU 2, 6.

Awang S.A.,2007 poltik kehutanan masyarakat,yogyakarta: kreasi wacana.

Baharuddin, Taskirawati I. (2009). Hasil Hutan Bukan Kayu. Makasar: Fakultas Kehutanan Universitas Hasanuddin

Balick,M.J.and R. Mandelsohn. 1992. Assessing the Economic Value of Traditioanal medicaines from Tropical Rain Forest.

Bringantoro, B.A. dan Nurrohcmat, D.R. 2007.Pemanfaatan sumber daya hutan oleh Masyarakat di KPH Banyuwangi utara.Departemen menajemen hutan.FakutasKehutanan.IPB. Bogor

Budinyanto.2009. Tingkat komsumsi kayu bakar masyarakat desa sekitar hutan.[skripsisFakultaskehutan ].IPB Bogor.

Dany, 2006.comodity notes, depertemen perdangan republik indonesia, jakarta.

Departemen Kehutanan RI. 2002. Informasi singkat benih Tamarindus indicaL.Artikel. Direktorat Perbenihan Tanaman Hutan. Bandung. No.21.

Harianja A. 2008 penata usaha hasil hutan di hutan rakyat (kasus di kabupaten humbang hasundatan dan samosir).dalam makalah hasil hutan penelitian.medan .3 desember 2008

Idris,S.2007.Tinjauan sosiologi lingkungan dalam pengelolaan hutan adat di desa baru Pangkalan jambu kabupaten merangin.Provinsi Jambi

International accounting standar board (IASB). 2004. Financial Instrumen: Discloserves and Oresebtatuib. International Accounting Standard No. 32. UK-IASB London

Ishak. 2016.Tingkat keterngatungan masyarakat petani $\mathrm{Hkm}$ dusung tunggulawung Terhadap sumber daya hutan gunung sasak Lombok barat.Universitas Mataram.

Kepala Desa Daha kecematan Hu'u kabupaten Dompu 2020. Hutan adalah sumber pendapatan dan aset penting bagi masyarakat

Korang Tempo. 2002. Belajar dari Skandal Enron, 5 Februari. Halaman 21. Jakarta

Lidiawati, I.2003.Penilaian ekonomi kerusakan hutan dan lahan akibat kebakaran.Institut Pertanianbogor.

Mangunwijaya, Y.B. 1992. Pendidikan Manusia Merdeka, 11 Agustus halaman15, Jakarta

Nazir,M. 2011. Metode penelitian. Ghalia Indonesia : Bogor.

Pemerintah RI. 1999. Undang-Undang Nomor 41 Tahun 1999 Tentang Kehutanan

Peraturan Mentri kehutanan Nomoe 35/MENHUT-11/2007.Tentang HHBK,

Rahmawaty, 2004.Hutan:fungsi dan peranannya bagi masyarakat,MSF pertanian -program ilmu kehutanan. Universitas Sumatera Utara.

Rubangi.2015.Kemiskinan masyarakat sekitar hutan studi kasus di pulau Lombok.Balai Penelitian teknologi hasil hutan bukan kayu.Lombok Barat.

Salim 2008.Hutan tumbuhan yang cukup luas hingga kelembaban, cahaya, suhu, tidak lagi menentukan lingkungan nya, Yogyakarta.

Sutomo. 2013. Hubungan karateristik sosial ekonomi dengan presepsi masayarakat pengelolaan Hutan kemasyarakatan tetang perubahan iklim di kawasan Hutang lindungKecematan Batu Keliaran Utara Kabupaten Lombok Barat Skripsi. Fakultas Kehutanan Universitas Mataram.

Tjitrosoepomo, G., 1993. Taksonomi Umum. Gadjah Mada University Press.

Undang-undang No.41 tahun 1999 pasal 40 tetang rehabilitas hutan.

Yogyakarta

Zain, AS. 1997. Aspek pembinaan Kawasan hutan dan stratifikasi hutan rakyat. PenerbitRinekaCipta. Jakarta. 